\title{
Patterns of Lesions in Hysterectomy Specimens in a Tertiary Care Hospital
}

\author{
Sujan Vaidya, ${ }^{1}$ Sapana Amatya Vaidya ${ }^{2}$ \\ 'Department of Pathology, Kathmandu Medical College, Sinamangal, Kathmandu, Nepal, ${ }^{2}$ Department of Obstertrics and \\ Gynaecology, Maternity Hospital, Thapathali, Kathmandu, Nepal.
}

\section{ABSTRACT}

Introduction: Hysterectomy is one of the most common gynaecological procedures performed all over the world. The most frequent indications for hysterectomy are fibroids, abnormal uterine bleeding uterovaginal prolapse and endometriosis. The objective of this study was to present the histopathological patterns of various uterine and adnexal pathologies in the hysterectomy specimens and also to correlate its pre-operative clinical diagnosis with histopathology.

Methods: This is a two-year descriptive study of hysterectomy specimens carried out in the Department of Pathology, Patan Academy of Health Sciences (PAHS), Lalitpur, Nepal. Data of all the hysterectomy specimens collected during this period was analyzed.

Results: Out of the 533 cases, fibroid was the most common indication for hysterectomy that was seen in 229 (42.94\%) cases followed by uterovaginal prolapse in 101 (18.93\%) cases. Leiomyoma was the most common pathology reported in 250 (46.90\%) hysterectomy specimens, followed by ovarian tumours in 95 (17.82\%) cases. In $17.82 \%(95 / 533)$ cases, no pathology was seen. Overall, the pre-operative indications in 533 cases of hysterectomy were histopathologically verifiable in $487(91.37 \%)$ cases.

Conclusions: Though the histopathological examination correlates well with the pre-operative clinical diagnosis, a number of lesions were also encountered as pure incidental findings. Hence, it is mandatory that every hysterectomy specimen should be subjected to histopathological examination so as to ensure better post-operative management.

Keywords: adenomyosis; hysterectomy; leiomyoma; tumour; uterovaginal prolapse.

\section{INTRODUCTION}

Uterus is a vital reproductive organ is subjected to many benign and malignant diseases. Many treatment options are available including medical and conservative surgical but hysterectomy still remains the most common gynaecological procedure performed worldwide. ${ }^{1}$
Since the early $20^{\text {th }}$ century, hysterectomy has been a definite treatment for pelvic pathology including fibroid, abnormal heavy menstrual loss, chronic pelvic pain, endometriosis, adenomyosis, uterine prolapse, pelvic

Correspondence: Dr. Sujan Vaidya, Department of Pathology Kathmandu Medical College, Sinamangal, Kathmandu, Nepal. Email: vaidyasujan@gmail.com, Phone: +977-9841416529. 
Vaidya et al. Patterns of Lesions in Hysterectomy Specimens in a Tertiary Care Hospital

inflammatory disease and cancer in the reproductive organs. $^{2}$

Hysterectomy can be performed by abdominal, vaginal or laparoscopic route and may or may not be accompanied by salpingo-oophorectomy of either one or both sides. Vaginal hysterectomy is performed predominantly for uterine prolapse, whereas abdominal hysterectomy is an indication for mostly menstrual disturbances and fibroids. At present, most of the hysterectomies performed worldwide are though the abdominal route. Even in the USA and UK, $60-80 \%$ of hysterectomies are performed via this route. ${ }^{3}$ In recent years, hysterectomy with laparoscopic assistance is increasingly being performed in developed and developing nations all over the world.

\section{METHODS}

This is a descriptive study of hysterectomy specimens carried out in the Department of Pathology, Patan Academy of Health Sciences (PAHS), Lalitpur, Nepal. All the hysterectomy specimens received by the Department of Pathology over a period of two years from June 2010 to May 2012 were included in the study.

Patient data retrieved from the medical records included age, indication of hysterectomy, type of operation, clinical indications and histopathological diagnosis. Histopathological findings from the cervix, endometrium, myometrium, ovaries and fallopian tubes were noted. Besides the physiological changes in the endometrium (proliferative, secretory and atrophic endometria), chronic cervicitis, functional cysts of ovary (inclusion cysts, cystic follicles, follicular cysts and luteal cysts) and paratubal cysts were considered histologically "unremarkable." Data was analyzed and statistical analysis done using SPSS version 17.

\section{RESULTS}

A total of 533 hysterectomies were performed during a two-year study period. The abdominal route (total abdominal hysterectomy or TAH) was taken in $432(81.05 \%)$ cases, while vaginal one (vaginal hysterectomy or $\mathrm{VH}$ ) in $101(18.95 \%)$ cases (Table 1 ).

Overall, the mean age of patients undergoing hysterectomy was 46.98 years (age range: 8 - 85 years). Likewise, the mean age of patients undergoing total abdominal hysterectomy (TAH) and vaginal hysterectomy (VH) was 46.75 and 48.32 years, respectively.

\begin{tabular}{|c|c|}
\hline Type of hysterectomy & Total $(\%)$ \\
\hline Vaginal hysterectomy (VH) & $101(18.95)$ \\
\hline $\begin{array}{l}\text { TAH with preservation of both tubes } \\
\text { and ovaries }\end{array}$ & $36(6.75)$ \\
\hline $\begin{array}{l}\text { TAH with unilateral salpingo- } \\
\text { oophorectomy (USO) }\end{array}$ & $49(9.20)$ \\
\hline $\begin{array}{l}\text { TAH with bilateral salpingo- } \\
\text { oophorectomy (BSO) }\end{array}$ & $347(65.10)$ \\
\hline Total & $533(100)$ \\
\hline
\end{tabular}

\begin{tabular}{|ll|}
\hline \multicolumn{2}{|l|}{ Table 2. Age distribution of patients. } \\
\hline Age group (in years) & Total (\%) \\
$\leq 20$ & $1(0.18)$ \\
$21-30$ & $25(4.69)$ \\
$31-40$ & $115(21.58)$ \\
$41-50$ & $248(46.53)$ \\
$51-60$ & $90(16.89)$ \\
$\geq 60$ & $54(10.13)$ \\
Total & $533(100)$ \\
\hline
\end{tabular}

Out of the 533 hysterectomy cases, 248 (45.63\%) were done in the fourth decade followed by 115 (21.58\%) cases in the third decade (Table 2). An eight year old girl had also undergone total abdominal hysterectomy with bilateral salpingo-oophorectomy (TAHBSO) for a malignant ovarian tumour (immature tertoma) involving both the ovaries.

Clinical indications of hysterectomy varied from menstrual abnormalities to suspected pelvic malignancy. The various indications for hysterectomy are depicted in Table 3. Out of the total 533 cases, fibroid was the most common indication for hysterectomy, accounting for $42.94 \%$ (229) of the cases followed by uterovaginal prolapse and ovarian tumours in $18.93 \%$ (101) and $16.68 \%$ (89) cases, respectively.

Emergency hysterectomy was indicated for post partum haemorrhage and placenta praevia. It accounted for $1.49 \%(8 / 533)$ cases of all hysterectomy specimens. Likewise, gestational trophoblastic disease (GTD) was an indication for hysterectomy in $6(1.13 \%)$ cases (Table 3).

Histopathological findings: Most of the hysterectomy specimens had one or more pathology on histopathological examination. Leiomyoma was the most common pathology that was reported in 250 (46.90\%) hysterectomy specimens, followed by ovarian tumours and adenomyosis in 95 (17.82\%) and $74(13.88 \%)$ cases, respectively. 
Vaidya et al. Patterns of Lesions in Hysterectomy Specimens in a Tertiary Care Hospital

\begin{tabular}{|ll|}
\hline Table 3. Indications for hysterectomy. \\
\hline Indications & Total (\%) \\
Fibroid & $229(42.94)$ \\
Dysfunctional uterine bleeding (DUB) & $37(6.93)$ \\
Uterovaginal prolapse & $101(18.93)$ \\
Pelvic inflammatory disease (PID) & $14(2.62)$ \\
Placenta praevia & $1(0.18)$ \\
Post partum haemorrhage (PPH) & $7(1.31)$ \\
Paratubal cysts & $2(0.38)$ \\
Endometriosis & $16(3.00)$ \\
Tubo-ovarian mass & $12(2.23)$ \\
Ovarian tumours & $89(16.68)$ \\
Cervical polyp & $3(0.56)$ \\
Cervical intraepithelial neoplasia (CIN) & $3(0.56)$ \\
Carcinoma of cervix & $5(0.92)$ \\
Endometrial polyp & $2(0.37)$ \\
Endometrial hyperplasia & $1(0.18)$ \\
Endometrial carcinoma & $5(0.92)$ \\
Molar pregnancy & $1(0.18)$ \\
Invasive mole & $1(0.38)$ \\
Choriocarcinoma & $4(0.73)$ \\
Total & $533(100)$ \\
\hline
\end{tabular}

Overall, malignant tumors were reported in 6.19\% (33/533) cases of hysterectomy, whereas premalignant/ potentially malignant conditions (hyperplasia, cervical intraepithelial neoplasia (CIN), borderline tumors, molar pregnancy and smooth muscle tumor of undetermined significance (STUMP) were noted in $48(9 \%)$ cases.

Endometrium: Endometrial pathology was present in $17.45 \%$ (93/533) hysterectomy specimens whereas it was histologically unremarkable (proliferative, secretory and atrophic endometria) in 440/533 (82.55\%) cases (Table 4). Endometrial hyperplasia was present in $4.88 \%$ $(26 / 533)$ cases of hysterectomy while malignancy was seen in $1.69 \%(9 / 533)$.

Myometrium: Myometrial pathology was seen in $61.54 \%(328 / 533)$ hysterectomy specimens. It was present in $72.22 \%(312 / 432)$ cases of abdominal hysterectomy and $15.84 \%(16 / 101)$ cases of vaginal hysterectomy.

Leiomyoma was the most common pathology which was seen in $46.9 \%(250 / 533)$ hysterectomy specimens, followed by adenomyosis in $13.88 \%(74 / 533)$ cases. In $8.07 \%(43 / 53)$ cases, both leiomyoma and adenomyosis were present. Also, three cases of uterine fibroid were histologically categorized as smooth muscle tumor of undetermined malignant potential (STUMP) while one case was diagnosed as a leiomyosarcoma.
Tubes and ovaries: Out of the 396 ovaries that were removed in 533 cases of hysterectomy (Table 1), ovarian pathology was observed in $34.1 \%$ (135/396). Ovarian tumors accounted for $70.37 \%$ (95/135) cases of ovarian pathology followed by endometriosis in $27 / 135(20 \%)$ cases (Table 5). Amongst the ovarian tumors, $66.32 \%(63 / 95)$ were benign, $18.95 \%$ $(18 / 95)$ were malignant whereas $14.73 \%$ (14/95) were borderline tumors. Serous cystadenoma was the most common benign ovarian tumor (28/63), whereas serous cystadenocarcinoma was the most common malignancy (7/18).

\begin{tabular}{|ll|}
\hline \multicolumn{2}{|l|}{ Table 4. Histopathological findings in the endometrium. } \\
\hline Histopathology of the endometrium & Total (\%) \\
Proliferative / secretory endometrium & $328(61.54)$ \\
Atrophic endometrium & $112(21.01)$ \\
Endometrial polyp & $19(3.56)$ \\
Endometritis & $11(2.06)$ \\
Pill endometrium & $4(0.75)$ \\
Disordered proliferative & $12(2.25)$ \\
endometrium & \\
Simple hyperplasia without atypia & $22(4.13)$ \\
Complex hyperplasia without atypia & $3(0.56)$ \\
Complex hyperplasia with atypia & $1(0.19)$ \\
Endometrioid adenocarcinoma & $5(0.94)$ \\
Clear cell carcinoma; endometrium & $1(0.19)$ \\
Gestational endometrium & $9(1.69)$ \\
Molar pregnancy & $2(0.38)$ \\
Invasive mole & $1(0.19)$ \\
Choriocarcinoma & $3(0.56)$ \\
Total & $533(100)$ \\
\hline
\end{tabular}

Cervix: The histopathological findings of the cervix are depicted in Table 6. Four cases of cervical intraepithelial neoplasia $(\mathrm{CIN})$ and five cases of cervical cancer were seen.

Incidental findings: In this study, various types of incidental findings were identified in numerous hysterectomy specimens. These findings are depicted in Table 7. Adenomyosis (60 cases) and leiomyoma (29 cases) were the most common incidental findings.

Unremarkable histopathology: Out of the 533 hysterectomy specimens included in this study, 95 $(17.82 \%)$ cases were histologically unremarkable. The commonest indication in these cases was uterovaginal prolapse which was seen in $82.1 \%$ (78/95) of the cases.

Of the 14 cases of pelvic inflammatory disease (PID) that had undergone hysterectomy, eight (57.14\%) cases did not show any abnormality. It was the most 
Vaidya et al. Patterns of Lesions in Hysterectomy Specimens in a Tertiary Care Hospital

common indication in the TAH group in which no pathology was seen.

Overall the pre-operative indications in 533 cases were histopathologically verifiable in 487 (91.37\%) cases. In the patients who had undergone hysterectomy for fibroids (229 cases), the final histopathology report confirmed the diagnosis in $211(92.14 \%)$ cases. However, in the 37 patients with pre-operative clinical diagnosis of dysfunctional uterine bleeding (DUB), the diagnosis was confirmed by histopathology in only 5 $(13.51 \%)$ cases.

\begin{tabular}{|ll|}
\hline \multicolumn{2}{|l|}{ Table 5. Histopathological findings in the ovaries. } \\
\hline Histopathology of ovaries & Total $(\%)$ \\
Normal histology / functional cysts & 261 \\
& $(65.90)$ \\
Endometriosis & $27(6.82)$ \\
Chronic non-specific salpingo-oophoritis & $10(2.53)$ \\
Tuberculous salpingo-oophoritis & $3(0.76)$ \\
Serous cystadenoma & $28(7.07)$ \\
Borderline serous tumour & $5(1.26)$ \\
Serous cystadenocarcinoma & $7(1.77)$ \\
Mucinous cystadenoma & $8(2.02)$ \\
Borderline mucinous tumour & $8(2.02)$ \\
Mucinous cystadenocarcinoma & $2(0.51)$ \\
Brenner tumour & $1(0.25)$ \\
Borderline Brenner tumour & $1(0.25)$ \\
Transitional cell carcinoma & $1(0.25)$ \\
Mature cystic teratoma & $24(6.06)$ \\
Squamous cell arising from dermoid cyst & $1(0.25)$ \\
Immature teratoma & $2(0.51)$ \\
Malignant mixed germ cell tumour & $1(0.25)$ \\
Choriocarcinoma & $1(0.25)$ \\
Fibroma & $2(0.51)$ \\
Adult granulosa cell tumour & $2(0.51)$ \\
Krukenberg tumour & $1(0.25)$ \\
Total & $396(100)$ \\
\hline
\end{tabular}

\begin{tabular}{|ll|}
\hline \multicolumn{2}{|l|}{ Table 6. Histopathological findings in the cervix. } \\
\hline Histopathology of cervix & Total (\%) \\
Chronic cervicitis & $515(96.62)$ \\
Cervical polyp (non-leiomyomatous) & $7(1.30)$ \\
Cervical leiomyoma & $2(0.38)$ \\
CIN I & $1(0.19)$ \\
CIN II & $1(0.19)$ \\
CIN III & $2(0.38)$ \\
Squamous cell carcinoma & $4(0.75)$ \\
Adenocarcinoma & $1(0.19)$ \\
Total & $533(100)$ \\
\hline
\end{tabular}

\begin{tabular}{|ll|}
\hline \multicolumn{2}{|l|}{ Table 7. Incidental histopathological findings. } \\
\hline Incidental histopathological findings & Total (\%) \\
Adenomyosis & $60(39.2)$ \\
Leiomyoma & $29(18.9)$ \\
Endometrial polyp & $16(10.4)$ \\
Endometriotic cyst & $11(7.1)$ \\
Benign ovarian tumours & $10(6.5)$ \\
Cervical polyp & $3(1.9)$ \\
Leiomyoma; cervix & $2(1.3)$ \\
Cervical intraepithelial neoplasia (CIN) & $2(1.3)$ \\
Disordered proliferative endometrium & $2(1.3)$ \\
Salpingo-oophoritis & $2(1.3)$ \\
Paratubal cyst & $1(.65)$ \\
Endometrial hyperplasia & $2(1.3)$ \\
Endometrial carcinoma & $2(1.3)$ \\
Retained POC & $1(0.65)$ \\
Pill endometrium & $1(0.65)$ \\
Total & $153(100)$ \\
\hline
\end{tabular}

\section{DISCUSSION}

Hysterectomy is one the common surgical procedures in the peri and post menopausal women; it is the second most common surgical procedure in the USA. ${ }^{4}$ According to the center of disease control and prevention, about five per 1000 women undergo hysterectomy annually year in USA and one in four women will have hysterectomy by the age of 60 years. ${ }^{5}$

It is an effective treatment option for many diseases, including benign and malignant tumours involving the uterus and its adnexae. It provides symptomatic relief, patient satisfaction and definitive cure in many of these diseases.

Hysterectomy can be performed by abdominal, vaginal or a laparoscopic route. Most gynaecologists around the world prefer the abdominal route. In the USA and UK $60-80 \%$ of hysterectomies are performed via this route. ${ }^{3}$ In our study, the abdominal route was taken in $81.05 \%(432 / 533)$ cases, while the vaginal one in $18.95 \%(101 / 533)$ cases. Laparoscopic assisted vaginal hysterectomy (LAVH) is not done in PAHS. Similar observations were made in the literature by Aksu et $\mathrm{al}^{6}{ }^{6}(82.74 \%)$, Gaym et $\mathrm{al}^{7}(77.3 \%)$ and Ranabhat et $\mathrm{al}^{8}(78.6 \%)$. However, in other studies from Nepal by Jha et al, ${ }^{9}$ Shrestha et al, ${ }^{10}$ and Pradhanang et al, ${ }^{11}$ the abdominal route was taken in only $62.9 \%, 49 \%$ and $44.7 \%$ cases, respectively.

Preference of the vaginal route over abdominal one in some of the studies from Nepal is probably due to a 
higher prevalence of uterovaginal prolapse in Nepal. ${ }^{11}$ The predisposing factors are early age of marriage, lack of post-natal rest, heavy workload and smoking habits of the rural women. ${ }^{12}$ Poverty stricken hardship, multiparity are other responsible factors.

The mean age of all patients undergoing hysterectomy was 46.98 years. Most of the hysterectomies were performed in the age group of $41-50$ years $(45.63 \%)$. These findings were similar to that observed by Rather et $\mathrm{al}^{13}(47.27 \%)$ and Pradhanang et al, ${ }^{11}(34.1 \%)$.

In this study, the most common clinical indication for hysterectomy was uterine leiomyoma in $42.96 \%$ $(229 / 533)$ cases followed by uterovaginal prolapse in $18.95 \%(101 / 533)$ cases which was consistent with the data reported by Nisa et $\mathrm{al}^{14}{ }^{14}(33 \%$ and $19 \%$, respectively) and Siwatch et al, ${ }^{15}$ (39\% and $22.6 \%$, respectively). Menorrhagia was the most common indication in similar studies by Rather et al, ${ }^{13}$ (35.43\%) and Saleh et al $^{16}(39 \%)$ whereas uterovaginal prolapse was the commonest indication in a study by $\mathrm{Jha}^{\mathrm{et}}$ al, ${ }^{9}$ (37.1\%).

Leiomyomas of the uterus are extremely common neoplasms. The overall incidence is between $4 \%$ and $11 \%$, but it rises to nearly $40 \%$ in women over the age of 50 years. These tumours occur subserosally, intramurally, or submucosally and produce symptoms referable to their size and location. ${ }^{17}$ In our study, leiomyoma was the most common pathology seen in the hysterectomy specimens $(46.91 \%)$. Similar observation was made in the studies by Abdullah ${ }^{18}$ (34.64\%), Ranabhat et $\mathrm{al}^{8}{ }^{8}(30.35 \%)$ and $\mathrm{Jha}$ et $\mathrm{al}^{9}{ }^{9}(27.15 \%)$.

Endometrial hyperplasia is a precursor of endometrial cancer. ${ }^{17}$ The classification used by the World Health Organization (WHO) designates four different types of hyperplasia. Hyperplasia is classified as simple or complex based on the absence or presence of architectural abnormalities such as glandular complexity and crowding. They are further designated as atypical if they demonstrate nuclear atypia. ${ }^{19,20}$ Endometrial hyperplasia was seen in $4.88 \%(26 / 533)$ hysterectomy cases. Similar data has been published in the literature by Jha et $\mathrm{al}^{9}{ }^{9}(4.52 \%)$ and Rather et $\mathrm{al}^{13}(4.44 \%)$. However, in a study by Saleh et al, ${ }^{16}$ a much higher incidence $(12.41 \%)$ of endometrial hyperplasia was reported.

Endometrial adenocarcinoma is the most common malignant tumour of the uterine corpus and is divided into endometrioid (usual) and special variant types. ${ }^{21}$ In this study there were 6 cases of endometrial carcinomas which were seen $1.13 \%$ (6/533) hysterectomy specimens which was comparable to other studies by Jha et $\mathrm{al}^{,}{ }^{9}$ and Gupta et $\mathrm{al}^{, 22}$ were $0.9 \%$ and $1 \%$, respectively. However in other studies, a lower incidence was observed by Rather et $\mathrm{al}^{13}$ and Nisa et al, ${ }^{14}(0.52 \%$ and $0.69 \%$, respectively) while a higher incidence was reported by Saleh et al, ${ }^{16}(2.92 \%)$.

In this study, ovarian tumor was diagnosed in $17.82 \%$ (95/533) hysterectomy specimens. This data was similar to that observed by Ranabhat et al, ${ }^{8}(17.26 \%)$ and Jha et $\mathrm{al}{ }^{9}(18.55 \%)$. However, a lower incidence $(8.02 \%)$ was noted in a study by Rather et al. ${ }^{13}$

In our study, histopathological examination of $17.82 \%$ (95/533) hysterectomy specimens showed no pathology. In other studies by Jha et al, ${ }^{9}$ Saleh et al, ${ }^{16}$ and Siwatch et al, ${ }^{15}$ the data was in $38 \%, 10.22 \%$ and $3.9 \%$, respectively. Most of these cases belonged to the vaginal hysterectomy group. Out of the total 101 vaginal hysterectomies (VH) included in our study, 78 $(77.23 \%)$ cases did not show any pathology whereas this figure was only $3.94 \%(17 / 432)$ for abdominal hysterectomies (TAH). Likewise, the figures for $\mathrm{VH}$ and $\mathrm{TAH}$ reported by $\mathrm{Jha}$ et $\mathrm{al}^{9}{ }^{9}$ were $80.5 \%$ and $12.9 \%$, respectively whereas it was $42.1 \%$ and $5.1 \%$, respectively by Aksu et al. ${ }^{6}$

Adenomyosis is rarely diagnosed preoperatively and is still largely under diagnosed as it has no specific symptoms of its own. ${ }^{23}$ It is usually diagnosed after hysterectomy by histopathological examination. ${ }^{24}$ In our study, it was the most common incidental finding on histopathological examination and was seen in $11.26 \%$ $(60 / 533)$ cases. The corresponding figures in the literature by $\mathrm{Jha}$ et $\mathrm{al}^{9}{ }^{9}$, Siwatch et $\mathrm{al}^{1}{ }^{15}$, Saleh et al, ${ }^{16}$ and Ranabhat et al, ${ }^{8}$ were $17.19 \%, 18.9 \%, 27.74 \%$ and $28 \%$ respectively.

In this study, the correlation of the pre-operative clinical diagnosis with the final histopathological examination of the hysterectomy specimens was done. The results vary from one study to another. In our study, the preoperative diagnosis of the 533 hysterectomy specimens were verified by histopathological examination in 487 $(91.37 \%)$ cases, which was comparable to reports by Siwatch et al, (84\%) and Lee et al, ${ }^{25}$ (80\%). However, Miller et $\mathrm{al}^{2}{ }^{26}$ reported that the clinical diagnosis was confirmed by histopathology in only $50 \%$ of the cases. Likewise, in our study the correlation of the preoperative clinical diagnosis for fibroids and DUB with the final histopathological diagnosis was $92.14 \%$ and $13.51 \%$, respectively. Similar observations were made by Saleh et al, ${ }^{16}(88.24 \%$ and $16.7 \%$, respectively).

\section{CONCLUSIONS}


Vaidya et al. Patterns of Lesions in Hysterectomy Specimens in a Tertiary Care Hospital

A wide range of lesions was encountered on histopathological examination. Though the histopathological examination correlates well with the pre-operative clinical diagnosis, a number of lesions were also encountered as pure incidental findings. Hence, it is mandatory that every hysterectomy specimen should be subjected to histopathological examination so as to ensure better post-operative management.

\section{REFERENCES}

1. Wu JM, Wechter ME, Geller EJ. Hysterectomy rates in the United States 2003. Obstet Gynecol. 2007;110(5):1091-5.

2. Nausheen F, Iqbal J, Bhatti FA, Khan AT, Sheikh S. Hysterectomy: The patient's perspective. Annals Gynecol. 2004;10:339-41.

3. Sobande AA, Eskander M, Archibong EI, Damole IO Elective hysterectomy: A clinicopathological review from Abha catchment area of Saudi Arabia. West Afr J Med. 2005;24:31-5

4. Graves EJ. National Center for Health Statistics, National Hospital discharge survey: annual summary, 1990. Viral Health stat (13). 1992, No. 112. DHHS Publication PHS 92-1773.

5. Bren L. Alternative to hysterectomy: new technologies, more options. FDA Consumer. Rockville: 2001;Vol 35:6;23.

6. Aksu F, Gezerand A, Oral E. Seventeen-year review of hysterectomy procedures in university clinic in Istanbul (1985-2001). Archives of Gynecology and Obstetrics. 2004;4:217-22.

7. Gaym A. Elective hysterectomy at Tikur Anbessa Teaching Hospital, Addis Ababa. Ethiop Med J. 2002;40(3):217-26.

8. Ranabhat SK, Shrestha R, Tiwari M, Sinha DP, Subedee LR. A retrospective histopathological study with or without salpingooophorectomy specimens. JCMC. 2010;1(1):26-9.

9. Jha R, Pant AD, Jha A, Adhikari RC, Sayami G. Histopathological analysis of hysterectomy specimens. J Nep Med Assoc. 2006;45:283-90.

10. Shrestha NS, Saha R, Karki C. Changing routes of hysterectomy: a cross sectional and comparative study. Nepal Med Coll J. 2010;12(3):176-9.

11. Pradhanang V, Tuladhar H, Maskey S, Dali SM, Pradhan P. Review of Hysterectomies at NMCTH: A Retrospective Study. J Nepal Health Res Counc. 2005;3(1):34-8.

12. Ratnam SS, Utero-vaginal prolapse. Obstet and Gynecology for Post Graduates 1994; Vol 2:437-53.

13. Rather GR, Gupta Y, Bhardwaj S. Patterns of Lesions in Hysterectomy Specimens: A Prospective Study. J K Science. 2013;15(2):63-8

14. Nisa Q, Hemlata, Habibullah, Memon F, Shaikh TA, Memon Z. Hysterectomies: An Audit at a Tertiary Care Hospital. Professional Med J. 2011;18(1):46-50.
15. Siwatch S, Kundu R, Mohan H, Huria A. Histopathologic audit of hysterectomy specimens in a tertiary care hospital. Sri Lanka J Obstet Gynaecol. 2012;34(4):155-8.

16. Saleh SS, Fram K. Histopathology diagnosis in women who underwent a hysterectomy for a benign condition. Arch Gynecol Obstet. 2012;285:1339-43.

17. Rosai J. Female reproductive system- uterus-corpus. In: Rosai and Ackerman's Surgical Pathology. 9th ed. Missouri; Mosby: Elsevier; 2005:1570-1648.

18. Abdullah LS. Hysterectomy: A Clinicopathologic Correlation. Bahrain Medical Bulletin. 2006;28(2):1-6.

19. Baral R, Pudasaini S. Histopathological pattern of endometrial samples in abnormal uterine bleeding. Journal of Pathology of Nepal. 2011;1:13-6.

20. Khare A, Bansal R, Sharma S et al, Morphological Spectrum of Endometrium in Patients Presenting with Dysfunctional Uterine Bleeding. People's Journal of Scientific Research. 2012;5(2):13-6.

21. Longacre TA, Atkins KA, Kempson RL, Hendrickson MR The uterine corpus. In: Sternberg's Diagnostic Surgical Pathology. Mills SE ed. $5^{\text {th }}$ ed. Philadelphia: Lippincott Williams \& Wilkins; 2010:2184-277.

22. Gupta G, Kotasthane DS, Kotasthane VD. Hysterectomy: A clinic-pathological correlation of 500 cases. Internet Gynaecol Obstetrics. 2010;14(1):1-6.

23. Weiss G, Maseelall P, Schott LL, Brockwell SE, Schocken $\mathrm{M}$, Johnston JM. Adenomyosis is a variant, not a disease? Evidence from hysterectomised menopausal women in the Study of Women's Health across the Nation (SWAN). Fertil Steril. 2009;91(1):201-6.

24. Shrestha A, Shrestha R, Sedhai LB, Pandit U. Adenomyosis at hysterectomy: prevalence, patient characteristics, clinical profile and histopathological findings. Kathmandu Univ Med J. 2012;37(1):53-6

25. Lee NC, Dicker RC, Rubin G, Oray HW. Confirmation of the pre-operative diagnosis for hysterectomy. Am J Obstet Gynecol. 1984; 150(3):283-7.

26. Miller NF, Hysterectomy: therapeutic necessity or surgical racket? Am J Obstet Gynecol. 1946;51:804. 